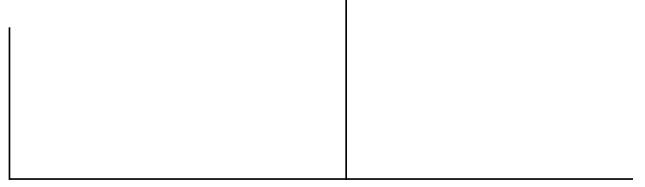

Rev. Latinoam. Psicopat. Fund., VI, 4, 182-185

Marianne Leuzinger-Bohleber, Ulrich Stuhr, Bernhard Ruger and Manfred Beutel, "How to study the 'quality of psychoanalytic treatments' and their long-term effects on patients' well-being: a representative, multi-perspective follow-up study" Int. J. Psychoanal., 84: 263-290, 2003 Resenhado por: Maria Carolina Ciotola Bruno

\title{
Podem os clínicos aprender com pesquisas extra-clínicas?
}

É possível estudar a qualidade de um tratamento psicanalítico? E seus efeitos a longo prazo?

Foi tentando responder essas questões que os autores deste artigo desenvolveram uma ampla atividade de pesquisa empírica sobre o trabalho clínico psicanalítico.

Seus autores, pesquisadores do Instituto de Psicanálise da Universidade de Kassel, Frankfurt, Alemanha - "Kassel and Sigmund Freud-Institute" - abordam esse tema, da pesquisa empírica em psicanálise, com uma visão mais ampla, não só de pesquisadores, mas também de quem está dentro da clínica.

O texto traz, logo em seu início, o reconhecimento das duras críticas, da crescente preocupação e do ceticismo, quase generalizado, dos clínicos em relação a este tipo de pesquisa empírica. Posição que, por um lado, é partilhada pelos autores, que concordam que essas pesquisas ainda não desenvolvem adequados métodos de observação, de coleta de dados e de interpretação dos resultados de uma análise, dificuldade justificada pela especificidade do material no qual trabalha a psicanálise: "os processos inconscientes e fantasias" de um sujeito, processos que não podem ser diretamente medidos, e que, por isso, requerem o desenvolvimento de uma (nova) abordagem científica específica, para que assim possa ser observado, investigado e entendido na sua idiossincrasia. Por outro lado, os autores também reconhecem a 
enorme pressão, tanto pública quanto científica, para que a psicanálise prove seus efeitos como um método psicoterapêutico. Partindo disso, e pensando sobre estes dois lados, eles questionam: Iremos resistir a essa pressão, arriscando perder cada dia mais importância em relação ao público comum, médico e científico ou devemos tentar nos esforçar para formular e fazer valer nossos argumentos dentro desses discursos? Não devemos pelo menos tentar nos ocupar desses desafios e executar nosso próprio estudo empírico psicanalítico?

Este artigo relata a experiência de um grupo de psicanalistas que tentou enfrentar esses desafios.

Percebe-se no texto a tentativa da elaboração de uma compreensão especificamente psicanalítica sobre a qualidade, os resultados do trabalho, bem como qual metodologia e critérios científicos seriam específicos para a avaliação da psicanálise.

Para eles, a psicanálise oscila entre dois pólos opostos: de um lado, havendo o perigo de que vá se isolando em uma "torre de marfim", construída por ela mesma, perdendo cada vez mais importância para outros campos (sendo válida e aceita somente por ela mesma) e abstendo-se, com isso, de um (importante e saudável) diálogo interdisciplinar; de outro, há também o perigo de que essas pesquisas (empíricas quantitativas) possam fazer com que a psicanálise se submeta demais a metodologias que não são compatíveis ao seu objeto de estudo: os processos inconscientes, fantasias e conflitos.

Este estudo preocupa-se, portanto, em andar cuidadosamente olhando para esses dois pólos, discutindo e refletindo constantemente em cima destas questões.

O trabalho realizado foi retrospectivo, o que, para os autores, tem a vantagem de não influenciar no andamento do trabalho psicanalítico, mas também tem a desvantagem de só obter uma visão distanciada do trabalho.

Participaram da pesquisa 401 pacientes, que já haviam terminado sua análise há pelo menos quatro anos e 62 analistas, todos membros da German Psychoanalytic Association.

Os critérios adotados foram uma combinação de métodos qualitativos (entrevistas com os pacientes e seus analistas) e métodos quantitativos (questionários de ansiedade, qualidade de vida, bem-estar, dados da utilização de serviço médico antes, durante e depois do tratamento). Outros dados que também foram coletados: os do diagnóstico (CID-10), a sintomatologia do início também é medida, caso o sujeito ou o analista a mencione durante as entrevistas, gravidade da psicopatologia no início e na época da pesquisa.

Dos 401 pacientes, apenas 129 participaram da entrevista.

As entrevistas foram feitas por 62 analistas de toda Alemanha, formando nove diferentes grupos de pesquisa, sendo que cada grupo entrevistaria pacientes de cidades diferentes das suas. 
Os autores entendem essas entrevistas como método de pesquisa "genuinamente psicanalítico", com entrevistas abertas, usando o método de associação livre, observando a transferência e contratransferência. A partir dessas entrevistas foram levantadas hipóteses clínicas, percebendo tanto a visão consciente quanto inconsciente do trabalho psicanalítico desenvolvido com cada sujeito.

Foram feitas duas entrevistas, sendo que, na primeira, o entrevistador abre um “espaço intermediário”, não-estruturado, para que os sujeitos falem abertamente (consciente ou inconsciente) de sua experiência de análise, em que também se tenta obter informações, tanto as manifestas quanto as latentes (inconscientes) a respeito da interação entre o sujeito e o entrevistador; no final desta primeira entrevista o entrevistador passa para uma parte semi-estruturada, com o objetivo de saber as razões do tratamento, a avaliação subjetiva deste e qual a motivação de participar dessa pesquisa. Após a primeira entrevista o pesquisador grava suas impressões e informações a respeito do sujeito e as discute com um supervisor do seu grupo de pesquisa.

A segunda entrevista começa também aberta, para que se possa observar e refletir sobre os possíveis efeitos da primeira entrevista, e só depois disso o entrevistador passa a questionar mais diretamente sobre a visão do sujeito a respeito de sua experiência de análise, sua relação com o analista, os efeitos (ou não) sobre os sintomas, o significado pessoal do tratamento para o sujeito, os eventos da sua vida anterior, durante e depois da análise, pedindo, ao final, que faça uma avaliação global de sua experiência de análise.

Há uma entrevista com o analista de cada paciente, sem que se passe qualquer informação a respeito da entrevista do sujeito, e para que este possa dar sua visão a respeito do trabalho com este paciente.

Ao final há uma discussão do caso com todos os membros do grupo, juntase o resultado dos testes com o das entrevistas, para só depois verificarem se a entrevista com o analista é compatível com a do paciente, examinando e refletindo a proximidade ou não dos dois discursos.

Em linhas gerais, os resultados até o momento foram os seguintes:

- Do grau de severidade, 76,7\% dos pacientes disseram que seu bem-estar geral estava seriamente comprometido antes da análise (de acordo com as escalas: $50.8 \%$ dos pacientes sofriam de transtorno de personalidade, $27.3 \%$ de transtornos afetivos, $10.9 \%$ de transtornos neuróticos e $6.3 \%$ de esquizofrenia - sendo que 22.5\% destes sujeitos teriam mais de três diagnósticos), 83,7\% destes pacientes relataram melhora no seu bem-estar após o trabalho psicanalítico, destes 83\%, dois terços disseram que o bem-estar perdurara até o momento da pesquisa (sendo que os pesquisadores compararam os progressos nas queixas psíquicas, físicas, nos relacionamentos interpessoais, capacidade de trabalho, tanto do ponto de vista do paciente quanto do analista). 
- 75\% relataram melhora de auto-estima e humor.

- O número de pacientes com relacionamento afetivo estável aumentou de $67 \%$ para $76 \%$ durante e depois da análise.

- 76\% dos pacientes estão satisfeitos com o trabalho.

- $65 \%$ dos analistas estão satisfeitos com o trabalho junto ao paciente.

- Houve redução bastante significativa (79\%) no número de dias que esses pacientes ficaram internados, assim como no número de consultas ao ambulatório de psiquiatria e faltas ao trabalho durante o trabalho psicanalítico.

Esses são apenas alguns resultados, mas que já nos abre espaço para muitas reflexões e discussões.

Os autores, ao terminarem o artigo, colocam, entre outras, a questão: O que os clínicos podem aprender com pesquisas extra-clínicas?

Eles entendem que se estas pesquisas se tornarem a "questão clínica central” de um tratamento (onde todo o trabalho teria que ser controlado) elas "não ajudam em nada”, até atrapalhariam muito, mas, por outro lado, de acordo com os 62 analistas envolvidos na pesquisa, essa foi uma experiência muito enriquecedora para a sua clínica, com observações novas do seu trabalho, fazendo com que refletissem a respeito dos "benefícios reais" decorrentes do trabalho analítico, podendo, através dessa pesquisa, também apresentar e expor dados mais "concretos" de alguns dos resultados de seu trabalho o que, para eles, foi muito bem recebido, além de coletar dados interessantes a respeito da clínica:

- As diferentes escolas e linhas psicanalíticas não apresentaram diferenças em seus resultados.

- Os analistas mostraram uma enorme adaptação, flexibilidade e abertura para cada caso atendido, onde "sua técnica era orientada prioritariamente para as necessidades do paciente, não baseada em suas convicções e crenças”.

- Os pesquisadores detectaram que o diagnóstico e a gravidade deste eram o menos decisivo no prognóstico do tratamento analítico.

- Os pacientes borderlines que tiveram bons resultados na pesquisa foram os que tiveram analistas com maiores suportes pessoais (análise e supervisão) e institucionais durante o tratamento.

- Os pacientes psicóticos que tiveram resultados favoráveis foram os que possuíam um tratamento de cooperação entre o psiquiatra e/ou instituição e seu analista, contando com modificações técnicas, como o tratamento "face-a-face" e a maior freqüência de sessões.

Esses são apenas alguns resultados e dados dessa pesquisa. Mas ao entrar em contato com uma pesquisa como essa, a questão que fica é a seguinte: O que a psicanálise poderá ganhar ou perder ao seguir este caminho? 